\title{
Thinking from Undergraduate Education to Lifelong Education
}

\author{
Tiangui Xiao, Shaobo Zhang, Chao Wang, Xianyu Yang
}

Chengdu University of Information Technology, Chengdu Sichuan 610225, China

This work is funded by 2018 Major Project of University-level Education research and Reform for Graduate Students (No. 201807), 2017 Open Online Course of Sichuan Province“Medium Term Weather Forecast and Short Term Climate Prediction", Chengdu University of Information Technology Undergraduate Teaching Project (No. BKJX2019042, BKJX2019007, BKJX2019013)

\begin{abstract}
With the development of human society, the knowledge and experience created by mankind has shown an explosive growth. It is difficult to fully grasp it by relying on individual energy. Therefore, in order to ensure the normal operation of society, cultivate high-end technical talents and professional Refined development has become the inevitable direction of education and teaching, and undergraduate education is an efficient talent training model based on this. In addition, in order to better keep up with the development trend of the times, people should continue to learn and improve themselves. The country and society should also build a more complete lifelong education system to improve the comprehensive quality of our citizens and achieve our great revival. And keep working hard.
\end{abstract}

Keywords: Undergraduate and Master Education; Lifelong Education; Thinking; Development

Education is an important cornerstone of social development. With the continuous development of various disciplines, the society has higher and higher requirements for the professionalization of talents. Therefore, many majors in colleges and universities have established integrated undergraduate and master education systems, in order to be as short as possible Time to train high-level, high-quality professionals. However, after students complete their undergraduate and master's education and enter into social development, it does not mean that they will be done once and for all. They do not need to continue learning, they need to improve themselves and realize the good habits of lifelong learning. The society and the country should build a complete lifelong education system for this, which reflects the advanced nature of education and teaching in our country, realizes lifelong learning for all people, and effectively improves the national education level of our country, which has a very positive effect on the modernization and development of the country.

\section{The necessity of transition from integrated education of undergraduate and master to lifelong education}

\subsection{Lifelong education is the need for human sustainable development}

The so-called lifelong education refers to the social development and the harmonious development of each individual member and the full display of their potential, and the design of education and teaching forms of all ages are specially designed. After completing the undergraduate and master's education, students should not stop, they should continue to follow the needs of the times and social development with concentration to learn, and provide continuous output power for future work and life. Therefore, no matter from the perspective of personal development or social development, human lifelong learning and self-education are the basic guarantee for maintaining the sustainable development of society, and it is also a historical necessity after the high development of human society.

Copyright (C) 2020 Tiangui Xiao et al.

doi: 10.18282/le.v9i7.1495

This is an open-access article distributed under the terms of the Creative Commons Attribution Non-Commercial License

(http://creativecommons.org/licenses/by-nc/4.0/), which permits unrestricted non-commercial use, distribution, and reproduction in any medium, provided the original work is properly cited. 


\subsection{Lifelong education is the need of human beings to pursue truth, goodness and beauty}

First of all, "true" refers to truth. The development process of human cognition is the process of constantly pursuing and grasping the truth. Truth is not easy to obtain. Only after a large number of experiments, studies and certifications can it be mastered. Human beings are limited by their own growth and energy, and there are huge individual differences between individuals. Only when they are constantly in a state of learning can they continue to accumulate the motivation to move forward, so as to achieve the goal of understanding true knowledge and obtaining truth.

Secondly, the process of lifelong education is also the process of one's own growth, including the formation of a person's moral cultivation. A positive attitude towards life and a correct way of dealing with others are important foundations for ensuring the harmonious development of society. Therefore, only pay attention to lifelong education and continue to guide People's self-reflection can improve people's ideological realm, become broad-minded, and finally encourage people to be kind and helpful in their lives, and truly realize the inheritance of the concept of "goodness".

Finally, the lifelong education system allows people to form different aesthetic concepts at different ages, promotes the transformation and development of people's ways of thinking, greatly enriches people's lifestyles, and enables more innovative ideas in society to be realized, which is a stable society. The main driving force for progress.

\section{The basic principles and basic conditions of constructing a lifelong education system}

\subsection{People-oriented principle}

To build a lifelong education system, we must first adhere to the "people-oriented" education and teaching principle, that is, according to the characteristics of human growth, develop reasonable education and teaching around people with different needs, and improve people's education and life quality as much as possible. Only by earnestly carrying out personalized lifelong education according to people's needs for knowledge, can the construction and development of a learning society be realized in a true sense.

\subsection{Government-led principles}

Building a lifelong education system not only requires individuals to have lifelong learning awareness, but more importantly, the joint efforts of the whole society. First of all, it is necessary for the government to issue relevant policies to provide a certain space for the development of non-governmental organizations, and to set up the necessary supervision mechanism based on the actual situation. However, as far as the current education situation is concerned, most members of the society have not realized the necessity and urgency of lifelong learning, and the awareness of actively participating in lifelong education is not strong enough. The departments still need governments at all levels to actively use relevant policies. To guide and regulate to ensure the sound development of lifelong education.

\subsection{The principle of adapting measures to local conditions}

The lifelong education system is the cornerstone of a learning society, and the educational development and social composition of each region are different. Therefore, in order to achieve the benign development of the learning society and steadily advance the realization of the lifelong education system, it is necessary to integrate the local reality According to the situation, according to the composition of the personnel structure, the direction of the main talent needs of the society, and the allocation of local public education resources, education and teaching reforms should be carried out in accordance with local conditions to truly apply what they have learned. Therefore, the construction of a lifelong education development system needs to be based on the characteristics of regional industries and human resource needs.

\subsection{Principle of scientific reliability}

The construction of a lifelong education system is a very complex dynamic process, which not only includes personal growth and development, but also a major adjustment and change in the overall social education and teaching atmosphere. Therefore, scientific methods should be used to analyze in detail people's attitudes and opinions on lifelong education at different levels and at different ages in society, and all data should be effectively integrated to find out the laws and improve the feasibility of building a lifelong education system. 


\subsection{Operational principles}

In addition to following the principles of scientific reliability, the construction of a lifelong education system must also consider the feasibility of its system construction, combined with people's educational and teaching needs, to make it feasible in theory and technology. A more specific analysis, first of all, is the availability of materials, which refers to the fact that education could have obtained as detailed as possible the education and teaching materials, as well as the archives and statistical reports of the education department. Only by improving the early information collection can it be a follow-up system. Prepare for the build. Secondly, it is a technical feasibility study, that is, choosing an appropriate method to implement a lifelong learning system so that people can implement lifelong education conveniently and efficiently.

\section{Concluding remarks}

Now our country is undergoing major changes unseen in a century. It requires the joint efforts of all sectors of society and all people to overcome this difficulty. Therefore, in order to better enhance our country's comprehensive strength, we should continue to strengthen the education and training of talents. All countries should increase the importance of education and teaching. In this process, whether it is undergraduate education or general education, it is necessary to form the learning consciousness of lifelong education, and in continuous learning, broaden one's own professional ability, form compound professional talents useful to the society, and serve social construction At the same time, personal value is maximized.

\section{References}

1. Wang Cong, Xiong Geng. The strategic choice of higher education towards 2030: from lifelong education to lifelong learning[J]. Hubei Social Sciences, 2018, 000(003):167-172.

2. Ma Lihua, Liu Jing, Li Zhenglian. The promotion framework and thinking of lifelong education combining "top-down" and "bottom-up" in Korea[J]. Foreign Education Research, 2018, 45(11):114- 130.

3. Che Yajun. Promoting the formation of a lifelong education system with "education points"-Reflections on adult higher education in my country from the perspective of lifelong education[J]. Journal of Beijing Xuanwu Hongqi Amateur University, 2018, 000(002): 9-12 . 